\title{
Creating good habits: making reflection the norm
}

\begin{abstract}
The Nursing and Midwifery Council (NMC) states that midwives should reflect on their practice in order to highlight areas where changes might lead to improvements in future practice (NMC, 2018a). The Code (NMC, 2018b) also states midwives must be aware of, and mitigate as far as possible, any potential harm associated with practice. The importance of reflection cannot be underestimated in relation to providing high quality, safe and effective care in line with the standards expected by the NMC, employers and service users.

A previous article in this series (Power et al., 2018) discussed an innovative emodule supporting student midwives' employability, social awareness and preparedness for professional practice on qualification. This article will review the e-module through a different lens - that of the student. Alice will share her experiences from the student's perspective of how she feels engagement with this module will impact on her employment opportunities and future practice.
\end{abstract}

\section{Keywords:}

Employability; pre-registration midwifery education; qualification; reflection

\section{Context}

The e-module's assessment strategy was to reflect on the knowledge and understanding gained through engaging with the module's e-tivities, supported by the Changemaker Hub (Box 1): namely how employability skills, attitudes and behaviours were enhanced in preparation for preceptorship applications by reflecting on personal and peer performance in a simulated interview situation, creating a CV, devising a Changemaker Project and considering the professional, legal and ethical issues relating to practice.

\section{Changemaker at The University of Northampton}

The Changemaker Hub creates the space for students to explore social innovation, gain valuable work experience, meet employers, introduces the changing world of work and prepares students for life after University.

The University is committed to social innovation and because of years of development in the field of Social Entrepreneurship the University of Northampton became a Changemaker Campus in 2013. Changemaker Campuses form a global network of entrepreneurial students, faculties and community leaders who provide inspiration, connections and support to broaden 
the reach and impact of social innovation around the world, with the aim of making the world a better place to be. (University of Northampton. 2019)

Carter et al. (2017) found that critical thinking skills promote safe, effective midwifery practice. Consequently, this key skill should be integrated into the preregistration midwifery curriculum, thereby nurturing new generations of criticallyaware midwives. The first e-tivity in the module was to complete an Employability Skills Self-assessment tool. One of the skills identified by the tool was 'advocacy when opposed', which is an essential skill for practising midwives as identified in the Code which states midwives must ensure that service users 'rights are upheld and that any discriminatory attitudes and behaviours towards those receiving care are challenged' (NMC, 2018:6). It is important that women understand the risks and benefits of interventions and care they receive and it is the midwife's duty to have candid conversations to support them in making an informed decision.

Another key attribute identified by the tool was the ability to identify opportunities for positive change. It is important that the midwife of the $21^{\text {st }}$ century be innovative and proactive in creating opportunities for positive change to meet the increasingly complex needs of women and families in their care. As the coordinators of care where interprofessional working is indicated, the physical and emotional demands of the role increase (Chief Nursing Officers of England, Northern Ireland, Scotland and Wales, 2010). The Midwifery 2020 vision recognises that continuity of carer improves the quality, safety and satisfaction with maternity services (Chief Nursing Officers of England, Northern Ireland, Scotland and Wales, 2010; Power, 2016). There may be some resistance to this change; however, students midwives should be encouraged during their training and as preceptor midwives to be advocates for service improvement.

Alice found the curriculum vitae (CV) e-tivity useful in preparation for job applications. She drafted her CV using the online tool and submitted it to the Changemaker team for feedback. The recommendations made were useful in shaping a professional CV from the original draft. A well-drafted CV is crucial for future applications as it documents academic credentials, accomplishments and skills (University of Pennsylvania, n.d; Middleton, 2014), in the hope of impressing employers and securing an interview. That said, many National Health Service (NHS) midwifery positions are posted on NHS Jobs (2019) which does not require a CV to be uploaded. It does, however, allow the applicant to type the same information into fields which will self-populate onto applications so this e-tivity was helpful with that process.

Should an applicant be successful in securing an interview, they must be as wellprepared as possible, especially for midwifery posts where competition is high (Power et al., 2016) even though statistics in England show that approximately 2,500 midwives are trained each year, yet the workforce only increases by around 100 midwives per year, despite the national shortage of 3,500 midwives (Royal 
College of Midwives (RCM), 2016). This is due to an ageing workforce, lack of flexible working and long-term sickness (RCM, 2016). In preparation for preceptorship interviews Alice used the interview simulator from the Changemaker hub, which gave her the opportunity to practice answering generic interview questions.

Students were also given midwifery specific questions to give them an opportunity to research contemporary midwifery issues (Power and Briody, 2016). Students were put into pairs and conducted mock interviews to give them the opportunity to practice along with the opportunity to engage with peer observation and feedback. Mock interviews improve performance and confidence and are therefore useful learning opportunities (American National University, 2016); that said, it should be acknowledged that mock interviews do not always predict performance in real interviews as the stressors of a real-life interview are difficult to reproduce (Ayres, et al, 1998). Alice felt role-play with a peer was a valuable exercise because feedback was meaningful and productive, as both students had an understanding of the expectations of the role they will be applying for (American National University, 2016). Alice found giving feedback challenging as although her peer gave a strong presentation, they lacked confidence in some areas and would have benefitted from greater reference to national policies and guidelines. Alice, in turn, received constructive feedback which included working on her verbal communication skills to ensure she gets her point across clearly in an interview situation and revising the Code (NMC, 2018b) to develop confidence in spontaneously articulating how it informs practice.

Clear communication is essential for effective midwifery practice (NMC, 2018; CQC, 2019), therefore development of this skill within the module was an opportunity for positive change. Simply put, Changemaking is about 'spotting a social or environmental problem and having the skills and grit to do something about it (University of Northampton, 2019). One e-tivity tasked students with developing a midwifery focused Changemaker Project which they hoped would have a social impact on self, peers and the community.

The Code (NMC, 2018b) recognises that reasonable steps should be taken to meet the language needs of non-English speaking women to make care equitable (McCandlish, 2010). In 2011, the top three spoken languages of women cared for by Alice's clinical placement provider were English, Polish and Gujarati. The current caseload of women in her local community are from other Eastern European and Asian countries (LocalStats UK, 2011). Alice's group wanted to explore ways to break language barriers, as translation services are either no longer funded or are unreliable - which could be to the detriment of women and their families (Newall and Phillimore, 2012). Recommendations arising from the group discussion were to employ bilingual midwives to meet the needs of the demographics of the local community - these midwives would form a caseload of women whereby care would be delivered in the antenatal, intrapartum and 
postnatal periods by a core team. If bilingual midwives were not available, NHS funded courses could be made available to midwives, including British sign language.

Constructive feedback from mentors can be invaluable in enhancing students' progression, as this identifies current strengths and future learning needs of individuals. This discussion should demonstrate sensitivity to create a positive impact on students (NMC, 2008). One e-tivity asked, 'what makes a good mentor?' Common themes agreed in groups were someone who is: approachable, should openly share information and knowledge, giving honest feedback. Students may have negative experiences if the mentor lacks confidence, or feedback is not given in a timely manner in an appropriate environment. This is commonly due to time constraints in clinical areas (Elcock and Sharples, 2011). Currently, students are required to work $40 \%$ of their placement with their allocated sign-off mentor (NMC, 2008). However, new standards for student supervision will require the student to be assessed by practice supervisors, who will provide feedback to practice assessors. The assessor's role will be to periodically observe the student's progress, communicate with practice supervisors, and liaise with academic assessors to evaluate and recommend students for progression (NMC, 2018c). Student midwives must complete a three-year pre-registration midwifery programme of study, evidence of this learning must be demonstrated and fitness to progress is approved collaboratively by mentors in the clinical area and the approved educational institution (NMC, 2009).

\section{Lessons learned}

Midwives are committed life-long learners constantly refining their practice as a result of reflection which is integrated into the revalidation process. In order to develop and improve practice, it is important that they are critical thinkers who reflect in and on practice. This module encourages a culture of reflection in the pre-registration midwifery programme at the University of Northampton to prepare students for qualification and beyond. The module, in conjunction with the Changemaker Hub, provides students with opportunities to prepare for job applications by creating CVs and improving interview techniques which will be invaluable for 'standing out from the crowd' in a highly competitive field. The peer observation and feedback activity prepares them for their role as practice supervisors to ensure their practice is in line with the Code by 'sharing skills, knowledge and experience where appropriate' and reflecting and acting upon feedback to improve practice (NMC, 2018:09). 
[Type here]

\section{References}

American National University (2016) What are the benefits of mock interviews [online] Available from: https://www.an.edu/lifenotes/What-are-the-Benefits-ofMock-Interviews-20160606-0830 [Accessed on: 05.02.2019]

Ayres J, Chen P E, Edwards P, Keereetaweep T (1998) Communication apprehension and employment interviews. Communication Education. 47 (1) pp $1-17$

Care Quality Commission (CQC) (2019) 2018 survey of women's experiences of maternity care: Statistical Release. Newcastle: CQC

Carter A, Creedy D, Sidebotham M (2017) Critical thinking skills in midwifery practice: Development of a self-assessment toll for students. Midwifery. 50 (July 2017) pp. 184-192

Chief Nursing Officers of England, Northern Ireland, Scotland and Wales (2010) Midwifery 2020: Delivering expectations. Midwifery 2020 Programme, Cambridge

Elcock, K, Sharples K (2011) A Nurse's Survival Guide to Mentoring. London: Elsevier

LocalStats UK (2011) Wellingborough Census Demographics United Kingdom [online] Available from: http://localstats.co.uk/census-

demographics/england/east-midlands/wellingborough [Accessed on: 06.02.2019]

Middleton J (2014) How to Write and Impressive CV. Nursing Times. 110 (17) pp. 2A

Newall D, Phillimore J (2012) Delivering in the age of super-diversity [online] Available from: https://www.rcm.org.uk/news-views-and-

analysis/analysis/delivering-in-the-age-of-super-diversity [Accessed on: 06/02/2019]

NHS Jobs (2019) My Profile [online] Available from:

https://www.jobs.nhs.uk/xi/profile/f9430858f98aa5ebb598ccda2d86ca28/?actio $\mathrm{n}=$ display\&\&section_ref=70\&stepped=1\#sec_70 [Accessed on: 04/02/2019]

Nursing and Midwifery Council (NMC) (2018a) Written Reflective Accounts [online] Available from: http://revalidation.nmc.org.uk/what-you-need-todo/written-reflective-accounts/ [Accessed on: 24/01/2019]

Nursing and Midwifery Council (NMC) (2018b) The Code. London: Nursing and Midwifery Council

Nursing and Midwifery Council (NMC) (2018c) Realising professionalism: Standards for education and training. Part 2: Standards for student supervision and assessment. London: Nursing and Midwifery Council

Nursing and Midwifery Council (NMC) (2009) Standards for pre-registration Midwifery education. London: Nursing and Midwifery Council 
Nursing and Midwifery Council (NMC) (2008) Standards to support learning assessment in practice, NMC standards for mentors, practice teachers and teachers. London: Nursing and Midwifery Council

Power A, Dakri T, Irwin W (2018) Changemaker: Preparing student midwives for employability, qualification and beyond. British Journal of Midwifery 26 (4) 264-266

Power A (2016) Midwifery in the $21^{\text {st }}$ Century: are students prepared for the challenge? British Journal of Midwifery. 24 (1) 66-68

Power A, Briody, P (2016) Preparing for your preceptorship midwife interview: A student's guide. British Journal of Midwifery. 24 (7) 491-493

Royal College of Midwives (RCM) (2016) State of Maternity Services Report 2016. London: Royal College of Midwives

University of Northampton (2019) Changemaker Hub. Available from: https://www.northampton.ac.uk/student-life/changemaker/. [Accessed 03.05.19]

University of Pennsylvania (n.d) CV Guide [online] Available from: https://www.vpul.upenn.edu/careerservices/gradstud/CVguide.php\#top [Accessed on: 04/02/2019] 